\title{
Interpersonal Relationships Moderate the Effect of Faces on Person Judgments
}

\author{
Mirjam A. Tuk, Peeter W.J. Verlegh, Ale Smidts \\ and Daniel H.J. Wigboldus
}

Accepted for publication in the European Journal of Social Psychology

\begin{tabular}{|l|l|}
\hline \multicolumn{2}{|l|}{ ERIM REPORT SERIES RESEARCHINMANEMENT } \\
\hline ERIM Report Series reference number & ERS-2008-057-MKT \\
\hline Publication & September 2008 \\
\hline Number of pages & 28 \\
\hline Persistent paper URL & http://hdl.handle.net/1765/13185 \\
\hline Email address corresponding author & m.a.tuk@rug.nl \\
\hline Address & Erasmus Research Institute of Management (ERIM) \\
& RSM Erasmus University / Erasmus School of Economics \\
& Erasmus Universiteit Rotterdam \\
& P.O.Box 1738 \\
& 3000 DR Rotterdam, The Netherlands \\
& Phone: + 31 10 408 1182 \\
& Fax: $\quad+31104089640$ \\
& Email: info@erim.eur.nl \\
& Internet: $\quad$ www.erim.eur.nl \\
\hline
\end{tabular}

Bibliographic data and classifications of all the ERIM reports are also available on the ERIM website: www.erim.eur.nl 


\section{ERASMUS RESEARCH INSTITUTE OF MANAGEMENT}

\section{REPORT SERIES \\ RESEARCH IN MANAGEMENT}

\begin{tabular}{|l|l|}
\hline ABSTRACT AND KEYWORDS \\
\hline Abstract & $\begin{array}{l}\text { Previous research suggests that people form impressions of others based on their facial } \\
\text { appearance in a very fast and automatic manner, and this especially holds for trustworthiness. } \\
\text { However, as yet, this process has been investigated mostly in a social vacuum without taking } \\
\text { interpersonal factors into account. In the current research, we demonstrate that both the } \\
\text { relationship context that is salient at the moment of an interaction and the performed behavior, } \\
\text { are important moderators of the impact of facial cues on impression formation. It is shown that, } \\
\text { when the behavior of a person we encounter is ambiguous in terms of trustworthiness, the } \\
\text { relationship most salient at that moment is of crucial impact on whether and how we incorporate } \\
\text { facial cues communicating (un)trustworthiness in our final evaluations. Ironically, this can result } \\
\text { in less positive evaluations of interaction partners with a trustworthy face compared to interaction } \\
\text { partners with an untrustworthy face. Implications for research on facial characteristics, trust, and } \\
\text { relationship theories are discussed. }\end{array}$ \\
\hline Free Keywords & trust, facial characteristics, person perception, word-of-mouth, relationship norms \\
\hline Availability & $\begin{array}{l}\text { The ERIM Report Series is distributed through the following platforms: } \\
\text { Academic Repository at Erasmus University (DEAR), DEAR ERIM Series Portal } \\
\text { Social Science Research Network (SSRN), SSRN ERIM Series Webpage } \\
\text { Research Papers in Economics (REPEC), REPEC ERIM Series Webpage }\end{array}$ \\
\hline Classifications & $\begin{array}{l}\text { The electronic versions of the papers in the ERIM report Series contain bibliographic metadata } \\
\text { by the following classification systems: } \\
\text { Library of Congress Classification, (LCC) LCC Webpage } \\
\text { Journal of Economic Literature, (JEL), JEL Webpage } \\
\text { ACM Computing Classification System CCS Webpage } \\
\text { Inspec Classification scheme (ICS), ICS Webpage }\end{array}$ \\
\hline
\end{tabular}




\title{
Running Head: FACIAL TRUSTWORTHINESS IN DIFFERENT RELATIONSHIPS
}

Interpersonal Relationships Moderate the Effect of Faces on Person Judgments

Manuscript accepted for publication in the European Journal of Social Psychology.

\author{
Mirjam A. Tuk \\ University of Groningen \\ Peeter W.J. Verlegh \& Ale Smidts \\ Rotterdam School of Management, Erasmus University Rotterdam \\ Daniel H.J. Wigboldus \\ Radboud University Nijmegen
}

Author Note

Mirjam A. Tuk, Department of Marketing, University of Groningen, Groningen, The Netherlands; Peeter W. J. Verlegh \& Ale Smidts, Department of Marketing Management, Rotterdam School of Management, Erasmus University Rotterdam, The Netherlands; Daniel H. J. Wigboldus, Behavioural Science Institute, Radboud University Nijmegen, Nijmegen, The Netherlands.

This research was supported by the Erasmus Research Institute of Management (ERIM).

Correspondence concerning this article should be addressed to, Mirjam A. Tuk, Department of Marketing, University of Groningen, P.O. Box 800, 9700 AV, Groningen, The Netherlands. E-mail: m.a.tuk@rug.nl 


\begin{abstract}
Previous research suggests that people form impressions of others based on their facial appearance in a very fast and automatic manner, and this especially holds for trustworthiness. However, as yet, this process has been investigated mostly in a social vacuum without taking interpersonal factors into account. In the current research, we demonstrate that both the relationship context that is salient at the moment of an interaction and the performed behavior, are important moderators of the impact of facial cues on impression formation. It is shown that, when the behavior of a person we encounter is ambiguous in terms of trustworthiness, the relationship most salient at that moment is of crucial impact on whether and how we incorporate facial cues communicating (un)trustworthiness in our final evaluations. Ironically, this can result in less positive evaluations of interaction partners with a trustworthy face compared to interaction partners with an untrustworthy face. Implications for research on facial characteristics, trust, and relationship theories are discussed.
\end{abstract}


Interpersonal Relationships Moderate the Effect of Faces on Person Judgments

Faces are often very important when interacting with others. Not only do they express temporary states, faces are also often used to infer more stable traits. Recently, there has been a renewed interest in face perception (e.g., Bodenhausen \& Macrae, 2006). However, most research on faces and person perception occurred within a social vacuum, without any reference to the interpersonal relationship between the observers (i.e., participants) and the person being judged. We argue that the impact of facial cues on person evaluations crucially depends on the social context in which we encounter a person. For example, baby-facedness has a negative impact on the chances of winning elections (Todorov, Mandisodza, Goren, \& Hall, 2005), but increases the likelihood that one will get a job as a nurse (Zebrowitz \& Montepare, 2005). The current research examines whether the social relationship between the observer and the observed, and the actual behavior performed within this relationship context, moderate the impact of facial cues on person judgments.

One of the first characteristics that people infer when encountering an unfamiliar face is trustworthiness. Willis and Todorov (2006) showed that people are very fast in forming trustworthiness impressions based on facial characteristics (within $100 \mathrm{~ms}$ ). An increase in available time for making these judgments did not further increase the quality of these judgments. Out of several time-constrained trait inferences, $100 \mathrm{~ms}$ trustworthiness impressions showed the highest correlations with impressions formed after unlimited exposure time. People thus are very efficient in making trustworthiness inferences from faces, which parallels the important role of trust in social interactions (Simpson, 2007).

Importantly, facial characteristics may serve as cues that influence the extent to which people value behavioral information (Brownlow, 1992). Brownlow provided participants with 
information that suggested the source to be either relatively trustworthy or untrustworthy and (independently) either an expert or an inexpert. Subsequently she examined the degree of persuasiveness of the source. The source had either a baby face or a mature face. The results demonstrated that a differential degree of trustworthiness did not influence the persuasiveness of the source when this source had a baby face, whereas the degree of expertise did. The reverse was the case when the source had a mature face; trustworthiness but not expertise influenced the degree of persuasiveness of this source. Presumably, a baby faced person is a trustworthy source anyhow (Zebrowitz \& Montepare, 2005), irrespective of actual trustworthiness, and a mature face is able to communicate knowledgeability, even when expertise might be questioned. In this manner, facial characteristics of sources direct our attention towards different aspects of social interactions (either trustworthiness or expertise related information), or make us value the same information in a different way.

Hassin and Trope (2000) distinguish two types of processes underlying person judgments from face perceptions. The first process is labeled "reading from faces" (RFF); people use facial characteristics when they form an impression of a person's behavior and personality. Hassin and Trope showed that this process occurred only when the description about the behavior was ambiguous, not when this description was unambiguous. The second process is labeled "reading into faces" (RIF), and refers to the use of information about the personality in the perception and evaluation of facial characteristics. Respondents who were provided with information about two people and were asked to rate the accompanying faces on a variety of dimensions, rated these faces as more similar when the descriptions of these persons closely matched each other than when these descriptions differed from each other, even though 
these were exactly the same faces. In line with this, Claypool, Hugenberg, Housley and Mackie (2007) showed that people perceived familiar faces as more happy than unfamiliar faces.

In sum, faces influence the perception of personality characteristics and information about personality characteristics influences the perception of faces. The relationship between person evaluations and facial characteristics may be further moderated by interpersonal relationships. Especially when it comes to trustworthiness evaluations, the relationship you have with someone and the actual behavior performed are likely to be important factors of influence on the final evaluation as well. As Simpson (2007) argues, trustworthiness evaluations involve the self, the specific partner, and the behavior in a certain situation. This implies that the impact of facial trustworthiness on person evaluations might depend on the interpersonal context in which this face is encountered. In the current research, we propose that the interpersonal relationship between the observer and the observed constitutes an important social context variable that moderates the influence of facial impressions on person judgments. More specifically, we argue that interpersonal relationships influence the interplay between characteristics inferred from a person's face and the behavior of this person. For example, trustworthiness inferences based on facial characteristics probably play a different role when blind-dating a person than when buying pre-packed ice-cream from the same person.

\section{Relationships and facial cues}

Although there are several theories that distinguish and categorize different relationship types, Fiske's (1992) model of relationship frames provides a framework that is especially relevant when studying the trustworthiness of others. Fiske distinguished between four different types of relationships, and argued that these four types (or mixtures thereof) capture the entire spectrum of relationships among people. These four different types are communal sharing (CS; 
relationships with very close others), authority ranking (AR; relationships based on superiorsubordinate relationships), equality matching (EM; relationships based on equality and an equal exchange of favors), and market pricing (MP; relationships in which money is the underlying communality to exchange products, services, and favors and in which money is used to communicate the value of things). Subtle cues can communicate which relational frame is relevant for a specific interaction. For example, when a student enters a classroom, he knows that the people in the room are fellow students (EM relations), except for the person in front of the room, facing the other people. This person is the professor, with whom he has an AR relationship.

With respect to the role of relationships in trustworthiness judgments, Fiske (1992, p. 702) pointed out a key distinction between EM and MP relationships. EM exchanges involve trust and the implicit obligation to reciprocate, which is in contrast with the explicit contractual nature of economic exchange in MP relations. To illustrate, consider the following: When you buy a sweater from a salesclerk in a store (MP relationship), you can see and feel what you are buying, and you know the exact conditions of the exchange because you see the price on the tag. If you're unsatisfied, you can return it and get your money back. Compare this to a case where you are borrowing a sweater from an acquaintance (EM relationship): the other person trusts you with her sweater. If there is a small stain or a tear, it may be difficult to decide on the proper way to compensate the other. Furthermore, in contrast to buying a sweater where the exchange occurs simultaneously (you pay the price and get the sweater), borrowing a sweater means that the other person may ask for a comparable favor, but you don't know what will be asked or when it will be asked. Such a request for reciprocating the favor might not come at a convenient moment, or be of a different nature than you had in mind yourself (Cialdini, 2001). This lack of 
explicit regulations of exchange within EM results in a relatively greater reliance on interpersonal trust than within MP.

In line with Fiske's notion we argue that, when it comes to the exchange of products or related information, interpersonal trust plays a more important role within EM relations than within MP related interactions. In the current research, we aim to examine whether the impact of trustworthiness inferences based on facial cues differs between EM and MP relationships.

To study these issues, we focused on the exchange of product recommendations among consumers, which is referred to as "word of mouth". People's product evaluations are strongly influenced by word of mouth (Herr, Kardes, \& Kim, 1991). It goes without saying that the business world is very interested in strategies that can be used to stimulate word-of-mouth recommendations, such as providing a financial reward for making a recommendation (cf., Ryu \& Feick, 2007). Such strategies create social interactions that contain components of both equality matching and market pricing relationships. That is, the recommendations are common within EM relationships, but the presence of a financial reward introduces a clear MP component. Financially stimulated word of mouth thus provides an excellent context for the study of EM versus MP relationships in social interactions. Moreover, these kinds of recommendations provide an excellent background for studying trustworthiness, because it is unclear whether these recommendations are based on true enthusiasm towards a product, or on the desire for financial gain. The ambiguity of this financially motivated behavior creates some level of suspicion and distrust (Main, Dahl, \& Darke, 2007), and fosters the use of facial cues to evaluate the other person (see Hassin \& Trope, 2000).

Based on our earlier theorizing, we propose that the influence of facial trustworthiness cues differs between EM relationships and MP relationships. As trust is more important in EM 
relationships, facial cues for trustworthiness should have a stronger impact on the evaluations of agents within an EM relationship than within an MP relationship (Fiske, 1992). The relative importance of trust within EM versus MP relationships might differ depending on the precise nature of the interaction. However, within an EM relationship, one trusts a recommendation to be driven by genuine rather than financial motives, which is less the case within MP relationships. This prediction is in line with Simpson (2007), who argues that people mainly infer the trustworthiness of their interaction partner in trust-diagnostic situations. A financial motive for a recommendation is normal and accepted within MP relationships, but not within EM relationships, so that this behavior is more diagnostic for trustworthiness within EM relationships than within MP relationships. We predicted that word of mouth that is motivated by financial gain (untrustworthy behavior) is less expected from a person with a trustworthy face than from a person with an untrustworthy face. As a result, overall evaluations of the person with a trustworthy face will be less positive than evaluations of the person with a less trustworthy face. This effect should be moderated by relationship context, and occur only in relationship contexts in which (interpersonal) trustworthiness is important and is violated (financially rewarded recommendations within EM relationships). When the relationship context is one in which trust is less important and not violated (as is the case with rewarded recommendations within MP relationships), there should be less of a difference between evaluations of agents with trustworthy faces and agents with untrustworthy faces. If the trustworthiness expectations are not violated within an EM relationship (no financial reward), this should result in a positive instead of a negative effect of facial trustworthiness on agent evaluations. 
Study 1

The purpose of Study 1 was to examine whether the relationship (MP or EM) in which a financially rewarded recommendation occurs, moderates the impact of facial trustworthiness on agent evaluations.

\section{Method}

Participants. One hundred and ten students (62 male and 48 female, mean age $M=22.40$ years old) participated in exchange for a small gift.

Procedure. Participants sat behind computer screens, in individual cubicles. Relationship context (EM versus MP) and trust (Trustworthy versus Untrustworthy) were manipulated between subjects. Facial trustworthiness was manipulated by systematic variations of the shape of the eyes (round or narrow; Schul, Mayo, \& Burnstein, 2004) and mouth (regular or a little narrower, in order to give the impression that the lips are pressed together; DePaulo et al., 2003). These cues are commonly believed to leak information about untrustworthiness (see Anderson, DePaulo, Ansfield, Tickle, \& Green, 1999 for the null relationship between these beliefs and the actual diagnosticity of these cues). We used the program FACES 4.0 to construct several pairs of faces that differed only in terms of eye shape, and lip shape. We pretested these faces $(\mathrm{N}=26)$ and carefully selected the pair (see Appendix 1) that only differed significantly in degree of trustworthiness, $t(25)=2.72, p=.01$; the trustworthy face scored higher $(M=5.79$; $S D=1.76)$ than the untrustworthy face $(M=3.92 ; S D=1.80$; measured on a 9-point scale $)$, but did not differ in terms of likeability, attractiveness, intelligence and realism. To make sure that respondents really saw the faces and not just paid attention to the target scenario, the face (either the trustworthy or the untrustworthy one, randomly determined) first appeared on the left side of the screen, and after one second the following scenario appeared on the right side of the screen: 
This is Paul. Paul is a student [EM]/ who works for the promotion team of a new magazine [MP]. Imagine that you are having lunch in the college cafeteria. It is crowded and Paul asks whether he can share the table with you. Paul introduces himself and starts a conversation with you. He tells you about [EM]/ that he works for [MP] a new magazine, which is targeted at students. Paul is very enthusiastic about this magazine and tells you that it contains a lot of interesting interviews and can help you find traineeships and a job.

Paul gives you a coupon for a trial subscription at reduced rate and leaves the table. When you read the coupon, you find out that Paul will receive $10 \%$ of the subscription price, when you subscribe.

The bold sentences contain the manipulation of relationships. Since all respondents were students, and Paul was also a student, EM is the default type of relationship applicable to interactions like the above described (Fiske, 1992).

After reading the scenario, we asked respondents to evaluate Paul. We were mainly interested in a general evaluation of Paul, and therefore included the following scales: Paul is "sympathetic"; "friendly"; "credible"; "egoistic"; "annoying"; "irritating" and "pushy" (1 = totally disagree; $7=$ totally agree, negative items were reverse coded). After these dependent measures, we asked respondents whether they had the impression that Paul would receive money if they would subscribe to the magazine ('yes', 'no', or 'don't remember'), to check whether respondents indeed noticed the presence of the ulterior motive. Respondents then left the cubicle to receive a debriefing and their reward. 


\section{Results}

We excluded all respondents who did not indicate that Paul would receive money if they would subscribe, because this indicates that they missed the crucial information that would lead one to question the motives and trustworthiness of Paul. These were 38 respondents, leaving 72 participants ${ }^{1}$. Of these 38 respondents, there were relatively more respondents from the EM condition (26), than from the MP condition $(12) \chi^{2}(1)=8.50, p=.01$, which confirms the idea that the financial motive fits more within MP than within EM. There was no difference in number of respondents noticing the financial motive between the trustworthy (20) and the untrustworthy (18) face.

The evaluations of the agent were averaged into an 'agent impression' index $(\alpha=.82)$. An ANOVA with relationship frame and trust as independent variables revealed a main effect of relationship frame, $F(1,68)=5.66, p<.05$. Respondents were more positive about Paul when MP was the most salient relationship norm in the interaction $(M=4.43 ; S D=0.79)$ compared to when EM was the most salient norm $(M=3.96 ; S D=1.08)$. This is in line with our reasoning that the financial motive is less offending within the MP relationship frame than within the EM frame. More importantly, there was also a significant interaction effect between trust and relationship frame on general agent judgment, $F(1,68)=4.95, p<.03$. In the MP frame there was no difference in agent impressions between the trustworthy and the untrustworthy face, $F<$ 1 (see Table 1 for cell means and SD's). In the EM frame, the agent with the untrustworthy face was evaluated more favorable $(M=4.33, S D=0.99)$ than the agent with the trustworthy face $(M$ $=3.53, S D=1.04), F(1,68)=5.46, p<.05$. 
Facial Trustworthiness in Different Relationships 12

\section{Discussion}

The results of this first study are in line with our expectations. When an MP relationship frame was salient, facial trustworthiness did not significantly influence the evaluation of the agent motivated by a financial gain. However, when EM was salient, an agent recommending a product for a financial reward was evaluated less positively when he had a face that communicated trustworthiness (rather than untrustworthiness). These results demonstrate that the effects of facial cues are not as unequivocal as previously assumed, and stress the importance of investigating the interaction between facial cues and the social context in which they are perceived. Study 2 further examines the process by which relationship norms moderate the effects of facial cues.

Study 2

Trustworthiness inferences from facial cues are fast and automatic (Willis \& Todorov, (2006). In the second study, we examined whether relationship norms are of influence at this automatic level as well. In real life, salespersons usually don't explicitly communicate that they work for a store or company. Instead, the applicable relationship frame is activated in an unobtrusive manner, for example by a company logo on the person's shirt. In the second study, we examined whether unobtrusively activated relationship frames provide a norm that is used to interpret (ambiguous) behavior of word-of-mouth agents.

Aarts and Dijksterhuis (2003) showed that people who were exposed to pictures of a library (with the norm to be silent), tended to lower their voices in a subsequent task. Similarly, Aarts, Dijksterhuis and Custers (2003) demonstrated that activating a conformity norm (by priming respondents with words like comply, obey, and conform) caused people to behave more norm confirming. Norms thus may influence behavior in an automatic manner, without any 
conscious intent or awareness. In a similar vein, we predict that the mere activation of relationship norms will influence how we perceive and judge the behaviors of our interaction partners. In Study 2, we manipulated relationship norms unobtrusively, via a priming manipulation. In contrast to Study 1, the information presented in the word of mouth scenario is identical across all conditions. We expected a pattern of results similar to Study 1 . Study 2 intends to show that, although trust inferences based on facial cues are fast and automatic, they can be overruled by relationship norms that are activated by subtle environmental (relationship) cues.

Method

Participants. One hundred and six students (50 male and 56 female, mean age $M=21.00$ years old) participated in exchange for a small gift.

Procedure. Participants sat behind a computer screen, in individual cubicles. To activate the different relationship frames as unobtrusively as possible, we told participants that the experiment consisted of separate and unrelated parts. The first part (the relationship activation manipulation) was introduced as research on word recognition speed. This was a word search paradigm (adapted from Van den Berg, Manstead, van der Pligt, \& Wigboldus, 2006); participants got a $10 \times 9$ letter matrix, in which they had to search for 14 hidden words. In the MP relationship condition, these words were related to the marketplace (e.g., buying, costs, store). In the EM condition, the words were related to equal others (e.g., colleague, balance, reciprocal). A pretest confirmed that the words were categorized as belonging to the intended relationship, $t(92)=35.56, p<.01\left(M_{M P}=7.67, S D_{M P}=1.05 ; M_{E M}=3.73, S D_{E M}=0.71\right.$, measured on a 9-point scale where $1=$ typical EM and $9=$ typical MP). After completing the word-search task, the 'second' task was introduced. This was similar to the task in Study 1. 
Participants were again presented with a face (the same faces as used in Study 1), and a scenario. The scenario was adapted and read as follows:

"Imagine being allocated for a class assignment to Paul, a fellow student who you don't know. For a meeting, he brought a new magazine with him, which is focused on your field of study. An article from this magazine helps you make the assignment. Paul is very enthusiastic about the journal. After your meeting, he gives you his copy, so that you can have a closer look at it. When you are at home, you notice the following coupon:"

After pressing enter, a standard "member-get-member" coupon appeared on the screen. On the coupon, it was stated that the current member would receive a $€ 10$ gift voucher for every new member. Paul himself had already filled out his name and subscription number (we used a blue-color 'handwriting' font to indicate this). We asked respondents to judge Paul on the same scales as used in the first study, and checked again whether they indeed noticed the financial reward.

Results

We excluded respondents who did not notice the financial reward on the coupon ${ }^{2}$ (22 respondents, equally distributed across conditions, $\chi^{2}(1)<1$; which is in line with the unobtrusiveness of relationship activation in this study). We performed an ANOVA with the remaining 84 respondents with relationship frame and trustworthiness as independent variables and 'agent impression' $(\alpha=.84)$ as the dependent variable. The expected interaction between relationship frame and trustworthiness was significant, $F(1,80)=5.95, p<.05$ (see Table 2 for cell means and SD's). Specific comparisons demonstrated that when the EM relationship frame was made salient, an agent with an untrustworthy face was evaluated more positively $(M=4.89$, 
$S D=0.79)$ than an agent with a trustworthy face $(M=4.12, S D=1.00), F(1,80)=6.67, p=$

.01. Within the MP relationship context, there was no effect of trustworthiness $(F<1)$. Main effects of trustworthiness and relationship frame were not significant $\left(F^{\prime} s<1\right)$.

\section{Discussion}

In this second study, we replicated the effects of Study 1 and provided more insight into the process by which these relationship norms impact our evaluations. Relationship norms moderated the effect of facial cues on agent evaluations, even when they were made salient unobtrusively, by means of an unrelated task. Again, agents with untrustworthy faces were evaluated more positively than agents with trustworthy faces when EM norms were made salient, but not when MP norms were made salient. Within MP relationships, trust is less important, and behavior driven by financial motives is not untrustworthy. In line with this reasoning, we found a positive but insignificant effect of facial trustworthiness on final evaluations in Studies 1 and 2. The automatic and associative nature of these effects is demonstrated by the fact that we were able to obtain them even when the relationship frame was activated in an unobtrusive manner. Thus, although facial trustworthiness is inferred in an automatic and efficient manner, these inferences can be overruled by unobtrusively activated environmental (relationship) cues. The unobtrusiveness of this activation also excludes the possibility that participants used the information about the relationship to engage in deliberative, attributional inferences (see Johar, 2005).

Study 3

Studies 1 and 2 showed that the impact of facial cues on person evaluations depends crucially on the type of relationship that is salient. Within EM relationships, trust is important, and untrustworthy behavior is especially detrimental when first impressions of this person were 
trustworthy. However, as argued above, we hypothesize that the reversed effect of facial trustworthiness in the previous two studies is due not only to the greater importance of trust within EM, but also to the fact that the behavior may not be trustworthy within this relationship (receiving a financial reward for a product recommendation). This implies that, within EM, if the behavior is not untrustworthy (i.e., a recommendation not driven by financial motives), we should find the regular positive effect of facial trustworthiness on person evaluations. In order to test this prediction, we conducted a third study, in which we manipulated the behavior of the EM interaction partner to be either untrustworthy (a recommendation driven by financial motives) or not untrustworthy (a 'regular' recommendation not driven by financial motives). We expected that, within EM relationships, there will be a positive effect of facial trustworthiness on person evaluations if the behavior is not untrustworthy. In line with Studies 1 and 2, if the behavior is untrustworthy, this effect will reverse and people will evaluate a person with a trustworthy face less positively than a person with an untrustworthy face.

Method

Participants. Fifty students ( 37 male and 13 female, mean age $M=23.04$ years old) participated voluntarily.

Procedure. Respondents were recruited on the campus of a large European university and participated in a paper-and-pencil study. They were given a booklet and asked to go through this calmly and concentrated, without leafing back and forward through the booklet. The study was introduced as a research on person perception. After the cover page, they saw a picture of either a trustworthy face or an untrustworthy face, and were asked to form an impression about "Paul, a fellow student with whom you work together in a study group". After doing so, they 
continued to the next page where they again saw the picture of Paul, and read the target interaction, which was:

Imagine the following:

In one of the study-group meetings, Paul brought a magazine with him, which is focused on your field of study.

He is very enthusiastic about the magazine, and says that you should subscribe as well. According to Paul, the magazine really closely matches with your interests. He gives you his copy, so that you can have a closer look at it.

\section{At home, you notice to your surprise that Paul gets 10 euro for every new member} he recruits. He didn't mention this to you! (financial reward condition)/ At home, you notice that Paul does not receive a reward for recruiting new members (no financial reward condition).

The bold sentences contain the manipulation of the financial reward. Respondents were than asked to evaluate Paul on the same items as we used in Studies 1 and 2. On the next page, as a manipulation check, we asked respondents whether they remembered if Paul received money for a new subscriber (there were three answer options: "yes, he did", "no, he did not", and "I don't remember). Furthermore, we asked participants to recall their first impressions of Paul, purely based on the picture. Participants were asked to rate this impression on two scales, the trustworthiness $(1=$ trustworthy, $7=$ untrustworthy $)$ and an overall evaluation of Paul $(1=$ positive, $7=$ negative; scores on both scales were reversed such that a higher score corresponds with a more trustworthy and positive evaluation). 
Facial Trustworthiness in Different Relationships 18

\section{Results}

This time, all respondents correctly recalled whether Paul would receive money for a new subscriber or not. The manipulation checks regarding the first impression of Paul based on his facial appearance revealed no significant effects for the general evaluation $(p$ 's $>.28)$. There was a significant effect of facial trustworthiness on the trustworthiness evaluations, $F(1,46)=$ $7.05, p=.01)$. The trustworthy face was evaluated more trustworthy $(M=4.82, S D=1.36)$ than the untrustworthy face $(M=3.78, S D=1.35)$. There were no other significant main or interaction effects. These results confirmed the pretest of the faces, the faces differ in degree of trustworthiness, but not in more general evaluations.

We performed an ANOVA with trustworthiness and financial motive as independent variables and 'agent impression' $(\alpha=.81)$ as dependent variable. There was a significant main effect of financial motive, $F(1,46)=6.50, p=.01$. Respondents were more positive about Paul when he did not have a financial motive $(M=4.37, S D=1.09)$ than when he did have a financial motive $(M=3.70, S D=0.83$; see Table 3 for cell means and $S D$ 's). More importantly, this effect was qualified by a significant interaction effect between facial trustworthiness and financial motive, $F(1,46)=18.11, p<.001$. In line with Studies 1 and 2, specific comparisons revealed that when the financial motive was present, respondents evaluated Paul more positive when he had an untrustworthy face $(M=4.10, S D=0.61)$ than when he had a trustworthy face $(M=3.38, S D=0.85), F(1,46)=4.74, p<.05$.

Importantly, the results also revealed a positive effect of facial trustworthiness when there was no financial reward involved, $F(1,46)=14.80, p<.001$. In conditions where there was no financial reward involved, a recommendation agent with a trustworthy face was 
evaluated more positive $(M=4.98, S D=0.79)$ than an agent with an untrustworthy face $(M=$ $3.70, S D=0.99)$.

Discussion

The results of Study 3 replicate and extend the findings of Studies 1 and 2. We again showed that, within an EM relationship, a person with a trustworthy face can be evaluated less positive than a person with an untrustworthy face, when the behavior is untrustworthy (a product recommendation driven by financial motives). However, we also showed that, when the behavior was not untrustworthy, facial trustworthiness had a positive effect on overall agent evaluations.

In line with Simpson (2007), Study 3 showed that the effect of facial trustworthiness not only depends on the relationship context in which an interaction occurs, but also on the actual behavior of the agent. We found a negative effect of facial trustworthiness when the behavior was untrustworthy (i.e., driven by financial motives), but a positive effect of facial trustworthiness when the behavior was not untrustworthy (i.e., not driven by financial motives). This confirms our claim that the actual behavior of an interaction partner is of crucial importance for the final impact of facial characteristics on person evaluations.

\section{General Discussion}

The current studies examined how the social context and the traits inferred from facial characteristics interact when evaluating an interaction partner. We showed that facial characteristics that in general are valued positively, can result in less favorable evaluations, depending on both the importance of these characteristics, and the actual behavior of this

person. In other words, we find that the influence of facial characteristics is moderated by the social context and by the behavior of the interaction partner. 
In line with Fiske (1992), we argued and demonstrated in the first two studies that trustworthiness is more important when evaluating financially rewarded recommendations within an equality matching relationship than within a market pricing relationship. As a result, people use facial cues indicating (un)trustworthiness to a lesser extent within MP relationships than within EM relationships. Previous research emphasized the speed and automaticity by which we infer trustworthiness from a face (Willis \& Todorov, 2006). The results of Study 2 show that these fast inferences can be overruled by unobtrusively activated constructs. This suggests that the negative impact of facial trustworthiness on final evaluations is not due to a conscious and deliberative correction mechanism, but rather a more efficient process. The spontaneous facial inferences can easily be overridden by subtle cues in the social context.

With Study 3, we showed that, within equality matching relationships, the degree to which faces communicate trustworthiness does impact agent evaluations, but the direction of this evaluation crucially depends on the behavior performed by this person. Within such relationships, cues that indicate (a lack of) trustworthiness are important, and trustworthiness based on facial cues is quickly and easily inferred (Willis \& Todorov, 2006). When the behavior is not untrustworthy, people evaluate this person in line with their first impressions (based on facial characteristics), so that a trustworthy face leads to more favorable agent evaluations than an untrustworthy face. When the behavior is untrustworthy, this reverses. In that case, a person with a trustworthy facial impression is evaluated more negative than an agent with an untrustworthy facial impression. By manipulating the actual behavior of the agent, Study 3 showed that the effect of facial trustworthiness not only depends on the relationship context in which an interaction occurs, but also on the actual behavior of the agent. 
Finally, within MP relationships, facial cues indicating (un)trustworthiness did not significantly influence agent evaluations (although the means of both Study 1 and Study 2 indicate a positive effect of facial trustworthiness). We want to emphasize that we do not argue that trust is by definition not important within MP relationships. For example, if a salesperson helps you choose between two similar products, you will probably rely more on the advice if the salesperson is more trustworthy. However, recommendations from salespeople are often partly driven by an ulterior (financial) motive (cf., Campbell \& Kirmani, 2000), and people are therefore less likely to take these recommendations at face value, irrespective of whether this salesperson appears to be trustworthy or not. In the end, there is always the option that the salesperson recommends the most expensive product in order to make the highest profits, or the less expensive one because it is a left over from the previous season. Therefore, we argue that trust is relatively less important within MP relationships.

This is in line with the reasoning of Simpson (2007), who argues that people are especially likely to form trustworthiness impressions of their interaction partners in trust diagnostic situations. Financial motives are inherent to the nature of MP relationships, and so their occurrence is not very trust-diagnostic. Within EM relationships on the contrary, financial motives are uncommon, and a clear indication of (un)trustworthiness. In Studies 1 and 2, we used different methods to show that the evaluations based on facial characteristics are moderated by social context (relationship framing). In Study 1, the relationship manipulation was part of the target scenario that also contained the crucial behavioral information. In Study 2, the relationship manipulation was part of an unobtrusive priming method that was independent of the target scenario. Both methods resulted in the same interaction effect between facial trustworthiness and relationship frames on the evaluation of the agent. This indicates that the 
traits people infer from facial cues are moderated not only by explicitly communicated relationship norms, but also by a more subtle and unobtrusive activation of these norms, separate from the target interaction.

The current research has important implications for the research on face perception and trustworthiness. Hassin and Trope (2000) differentiated between 'reading from faces' (RFF; inferring personality traits from faces) and the 'reading into faces' (RIF; judging facial characteristics in line with information about personality). Our research deals with an RFF process, since we examined the impact of facial characteristics on person judgments. We showed that the social context in which we encounter others, is a crucial moderator of the RFF effect. People do not just infer personality traits from faces (the RFF process), they infer personality traits from faces and incorporate information about social contexts and the behaviors of these people into their final judgments about the personalities of these people. This context can be one in which the trait inferred from facial characteristics matches with the context, mismatches with the context, or is not relevant. Depending on the nature of this context, people seem to evaluate a person in line with the inferred characteristic, in contrast to the inferred characteristic, or independent of the inferred characteristic. The results suggest that this occurs at an unintentional level, and is not a more deliberative correction process that occurs only after inferring the personality traits. In daily life, people often are exposed first to the setting (e.g., they enter a store or a classroom) and only then encounter a person (the salesperson approaches; the teacher arrives). This makes it of crucial importance to examine the role of social situations in the impact of facial cues on person evaluations.

The current research suggests that people readily form expectations about interpersonal behavior based on both facial characteristics and interpersonal relationships. If the behavior 
mismatches with these expectations, this can result in evaluations that reflect a contrast effect to the initial inference one would make purely based on the facial characteristics. It may be expected that this effect also occurs for different other types of facial cues. Our research shows that facial characteristics are especially influential in situations that are diagnostic with regard to the trait that is under consideration. Within these situations, the impact of favorable facial characteristics can be either positive or negative, depending on the actual behavior of the person. 


\section{References}

Aarts, H., \& Dijksterhuis, A. (2003). The silence of the library: Environment, situational norm, and social behavior. Journal of Personality and Social Psychology, 84(1), 18-28.

Aarts, H., Dijksterhuis, A., \& Custers, R. (2003). Automatic normative behavior in environments: The moderating role of conformity in activating situational norms. Social Cognition, 21(6), 447-464.

Anderson, D. E., DePaulo, B. M., Ansfield, M. E., Tickle, J. J., \& Green, E. (1999). Beliefs about cues to deception: Mindless stereotypes or untapped wisdom? Journal of Nonverbal Behavior, 23(1), 67-89.

Bodenhausen, G. V., \& Macrae, C. N. (2006). Putting a face on person perception. Social Cognition, 24(5), 511-515.

Campbell, M. C., \& Kirmani, A. (2000). Consumers' use of persuasion knowledge: The effects of accessibility and cognitive capacity on perceptions of an influence agent. Journal of Consumer Research, 27(1), 69-83.

Claypool, H. M., Hugenberg, K., Housley, M. K., \& Mackie, D. M. (2007). Familiar eyes are smiling: On the role of familiarity in the perception of facial affect. European Journal of Social Psychology, 37(5), 856-866.

DePaulo, B. M., Malone, B. E., Lindsay, J. J., Muhlenbruck, L., Charlton, K., \& Cooper, H. (2003). Cues to deception. Psychological Bulletin, 129(1), 74-118.

Fiske, A. P. (1992). The four elementary forms of sociality: Framework for a unified theory of social relations. Psychological Review, 99(4), 689-723.

Hassin, R., \& Trope, Y. (2000). Facing faces: Studies on the cognitive aspects of physiognomy. Journal of Personality and Social Psychology, 78(5), 837-852. 
Herr, P. M., Kardes, F. R., \& Kim, J. (1991). Effects of word-of-mouth and product-attribute information on persuasion: An accessibility-diagnosticity perspective. Journal of Consumer Research, 17(4), 454-462.

Johar, G. V. (2005). The price of friendship: When, why, and how relational norms guide social exchange behavior. Journal of Consumer Psychology, 15(1), 22-27.

Main, K. J., Dahl, D. W., \& Darke, P. R. (2007). Deliberative and automatic bases of suspicion: Empirical evidence of the sinister attribution error. Journal of Consumer Psychology, 17(1), 59-69.

Ryu, G., \& Feick, L. F. (2007). A penny for your thoughts: Referral reward programs and referral likelihood. Journal of Marketing, 71(1), 84-94.

Simpson, J. A. (2007). Psychological foundations of trust. Current Directions in Psychological Science, 16(5), 264-268.

Todorov, A., Mandisodza, A. N., Goren, A., \& Hall, C. C. (2005). Inferences of competence from faces predict election outcomes. Science, 308(5728), 1623-1626.

Van den Berg, H., Manstead, A. S. R., van der Pligt, J., \& Wigboldus, D. H. J. (2006). The impact of affective and cognitive focus on attitude formation. Journal of Experimental Social Psychology, 42(3), 373-379.

Willis, J., \& Todorov, A. (2006). First impressions: Making up your mind after a 100-ms exposure to a face. Psychological Science, 17(7), 592-598.

Zebrowitz, L. A., \& Montepare, J. M. (2005). Appearance DOES matter. Science, 308(5728), 1565-1566. 
Appendix 1: Untrustworthy and Trustworthy Face
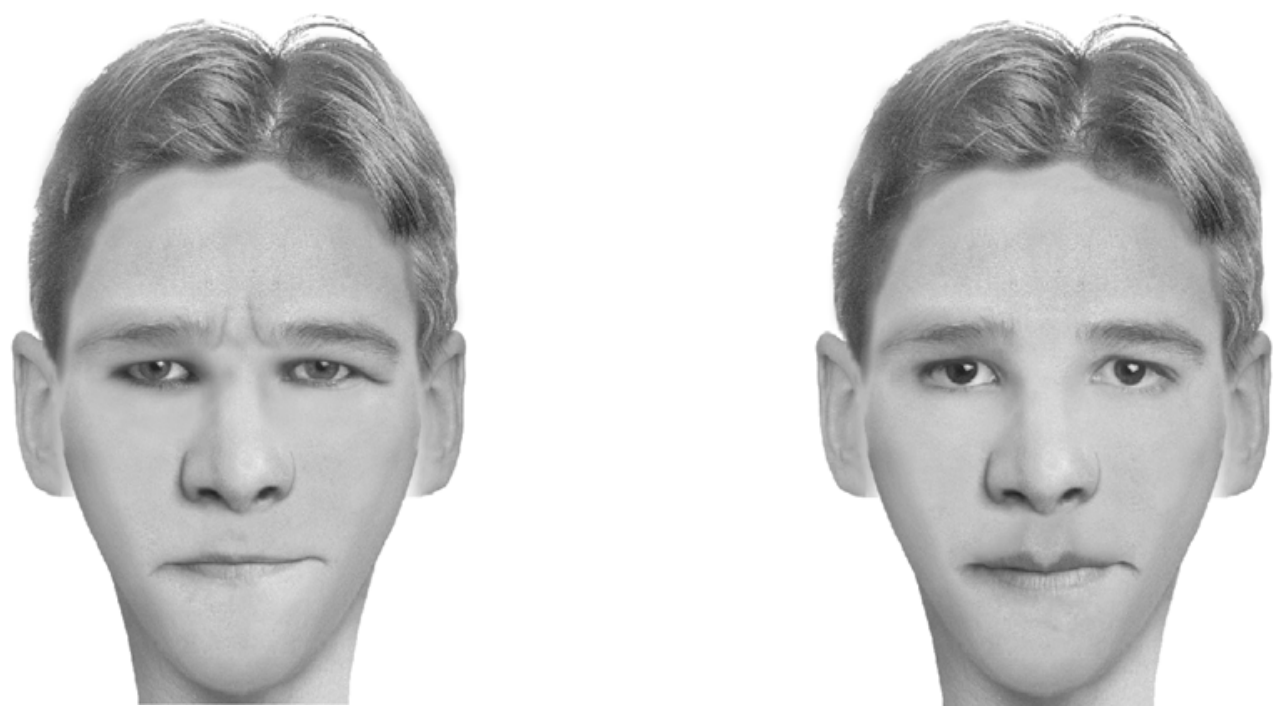

Untrustworthy face

Trustworthy face 


\section{Footnote}

${ }^{1} \mathrm{We}$ are aware of the fact that this is a large number of respondents to exclude. However, because the awareness of the financial motive (the ambiguous and potentially untrustworthy part of the behavior) is of crucial importance for testing our hypothesis, we can only draw reliable conclusions for respondents who did indeed notice these motives, which makes it necessary to exclude the respondents who did not notice the ulterior motive. If we do not apply this criterion, the results are in the same direction. The crucial contrast effect between the trustworthy and the untrustworthy face within $\mathrm{EM}$ was $F(1,106)=2.16, p<.15$; the agent with the trustworthy face was evaluated less positive $(M=3.86)$ than the agent with the untrustworthy face $(M=4.21)$. Furthermore, the contrast between the trustworthy and the untrustworthy face within MP was not significant, $F(1,106)<1$. In line with the expectations, within MP, the untrustworthy face $(M=4.38)$ and the trustworthy face $(M=4.45)$ did not differ in final evaluations.

${ }^{2}$ We excluded respondents according to the same criterion as mentioned in footnote 1 . If we do not exclude them, results are in the same direction, but marginally significant. The crucial contrast effect between the trustworthy and the untrustworthy face within EM was $F(1,105)=$ $3.14, p<.08$; the agent with the trustworthy face was evaluated less positive $(M=4.32)$ than the agent with the untrustworthy face $(M=4.80)$. Again, the contrast between the trustworthy and the untrustworthy face within MP was not significant, $F(1,105)<1$. In line with the expectations, within MP, the untrustworthy face $(M=4.45)$ and the trustworthy face $(M=4.58)$ did not differ in final evaluations. 
Table 1

Study 1 Means and SD's (in brackets) of agent judgment as a function of relationship frame and face trustworthiness

\begin{tabular}{lll}
\hline Relationship & Trustworthy face & Untrustworthy face \\
\hline EM & $3.53(1.04)$ & $4.33(0.99)$ \\
MP & $4.52(0.69)$ & $4.36(0.86)$ \\
\hline
\end{tabular}

Table 2

Study 2 Means and SD's (in brackets) of agent judgment as a function of relationship frame and face trustworthiness

\begin{tabular}{lll}
\hline Relationship & Trustworthy face & Untrustworthy face \\
\hline EM & $4.12(1.00)$ & $4.89(0.79)$ \\
MP & $4.48(0.98)$ & $4.23(1.05)$ \\
\hline
\end{tabular}

Table 3

Study 3 Means and SD's (in brackets) of agent judgment within EM as a function of the presence of a financial motive and face trustworthiness

\begin{tabular}{lll}
\hline & Trustworthy face & Untrustworthy face \\
\hline Financial motive absent & $4.98(0.79)$ & $3.70(0.99)$ \\
Financial motive present & $3.38(0.85)$ & $4.10(0.61)$ \\
\hline
\end{tabular}




\section{Publications in the Report Series Research ${ }^{*}$ in Management}

\section{ERIM Research Program: "Marketing"}

2008

Experts' Stated Behavior

Youssef Boulaksil and Philip Hans Franses

ERS-2008-001-MKT

http://hdl.handle.net/1765/10900

The Value of Analogical Reasoning for the Design of Creative Sales Promotion Campaigns: A Case-Based Reasoning Approach

Niek A.P. Althuizen and Berend Wierenga

ERS-2008-006-MKT

http://hdl.handle.net/1765/11289

Shopping Context and Consumers' Mental Representation of Complex Shopping Trip Decision Problems Benedict G.C. Dellaert, Theo A. Arentze and Harry J.P. Timmermans ERS-2008-016-MKT

http://hdl.handle.net/1765/11812

Modeling the Effectiveness of Hourly Direct-Response Radio Commercials

Meltem Kiygi Calli, Marcel Weverbergh and Philip Hans Franses

ERS-2008-019-MKT

http://hdl.handle.net/1765/12242

Choosing Attribute Weights for Item Dissimilarity using Clikstream Data with an Application to a Product Catalog Map Martijn Kagie, Michiel van Wezel and Patrick J.F. Groenen

ERS-2008-024-MKT

http://hdl.handle.net/1765/12243

The Effect of Superstar Software on Hardware Sales in System Markets

Jeroen L.G. Binken and Stefan Stremersch

ERS-2008-025-MKT

http://hdl.handle.net/1765/12339

Sales Growth of New Pharmaceuticals Across the Globe: The Role of Regulatory Regimes

Stefan Stremersch and Aurélie Lemmens

ERS-2008-026-MKT

http://hdl.handle.net/1765/12340

When Intelligence is (Dys)Functional for Achieving Sales Performance

Willem J. Verbeke, Frank D. Belschak, Arnold B. Bakker, and Bart Dietz

ERS-2008-034-MKT

http://hdl.handle.net/1765/12633

Path Dependencies and the Long-term Effects of Routinized Marketing Decisions

Paul Farris, Willem J. Verbeke, Peter Dickson and Erjen van Nierop

ERS-2008-035-MKT

http://hdl.handle.net/1765/12634

Does Irritation Induced by Charitable Direct Mailings Reduce Donations?

Merel van Diepen, Bas Donkers and Philip Hans Franses

ERS-2008-036-MKT

http://hdl.handle.net/1765/12704 
Brain Mechanisms of Persuasion: How "Expert Power" Modulates Memory and Attitudes

Vasily Klucharev, Ale Smidts and Guillén Fernández

ERS-2008-038-MKT

http://hdl.handle.net/1765/12784

Moderating Factors of Immediate, Dynamic, and Long-run Cross-Price Effects

Csilla Horváth and Dennis Fok

ERS-2008-042-MKT

http://hdl.handle.net/1765/12901

Why, How and When Do Prices Land? Evidence from the Videogame Industry

Carlos Hernandez-Mireles, Dennis Fok and Philip Hans Franses

ERS-2008-044-MKT

http://hdl.handle.net/1765/12900

Situation-Based Shifts in Consumer Web Site Benefit Salience: The Joint Role of Affect and Cognition

Sonja Wendel and Benedict G.C. Dellaert

ERS-2008-050-MKT

http://hdl.handle.net/1765/13179

Including Item Characteristics in the Probabilistic Latent Semantic Analysis Model for Collaborative Filtering

Martijn Kagie, Matthijs van der Loos and Michiel van Wezel

ERS-2008-053-MKT

http://hdl.handle.net/1765/13180

Cross-National Logo Evaluation Analysis: An Individual Level Approach

Ralf van der Lans, Joseph A. Cote, Catherine A. Cole, Siew Meng Leong, Ale Smidts, Pamela W. Henderson, Christian Bluemelhuber, Paul A. Bottomley, John R. Doyle, Alexander Fedorikhin, M. Janakiraman, B. Ramaseshan,

and Bernd $H$. Schmitt

ERS-2008-055-MKT

http://hdl.handle.net/1765/13181

Sales and Sincerity: The Role of Relational Framing in Word-of-Mouth Marketing

Mirjam A. Tuk, Peeter W.J. Verlegh, Ale Smidts and Daniel H.J. Wigboldus

ERS-2008-056-MKT

http://hdl.handle.net/1765/13183

Interpersonal Relationships Moderate the Effect of Faces on Person Judgments

Mirjam A. Tuk, Peeter W.J. Verlegh, Ale Smidts and Daniel H.J. Wigboldus

ERS-2008-057-MKT

http://hdl.handle.net/1765/13185

\footnotetext{
A complete overview of the ERIM Report Series Research in Management: https://ep.eur.nl/handle/1765/1

ERIM Research Programs:

LIS Business Processes, Logistics and Information Systems

ORG Organizing for Performance

MKT Marketing

F\&A Finance and Accounting

STR Strategy and Entrepreneurship
} 